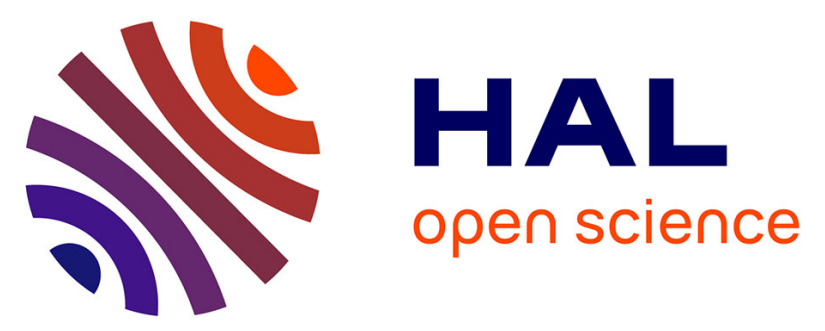

\title{
Decreased Cardiovascular and Extrahepatic Cancer-Related Mortality In Treated Patients with Mild HFE Hemochromatosis.
}

Edouard Bardou-Jacquet, Jeff Morcet, Ghislain Manet, Fabrice Lainé, Michèle Perrin, Anne-Marie Jouanolle, Dominique Guyader, Romain Moirand, Jean-François Viel, Yves Deugnier

\section{To cite this version:}

Edouard Bardou-Jacquet, Jeff Morcet, Ghislain Manet, Fabrice Lainé, Michèle Perrin, et al.. Decreased Cardiovascular and Extrahepatic Cancer-Related Mortality In Treated Patients with Mild HFE Hemochromatosis.. Journal of Hepatology, 2015, 62 (3), pp.682-689. 10.1016/j.jhep.2014.10.025 . hal-01091479

HAL Id: hal-01091479

https://hal-univ-rennes1.archives-ouvertes.fr/hal-01091479

Submitted on 5 Dec 2014

HAL is a multi-disciplinary open access archive for the deposit and dissemination of scientific research documents, whether they are published or not. The documents may come from teaching and research institutions in France or abroad, or from public or private research centers.
L'archive ouverte pluridisciplinaire HAL, est destinée au dépôt et à la diffusion de documents scientifiques de niveau recherche, publiés ou non, émanant des établissements d'enseignement et de recherche français ou étrangers, des laboratoires publics ou privés. 


\section{DECREASED CARDIOVASCULAR AND EXTRAHEPATIC CANCER- RELATED MORTALITY IN TREATED PATIENTS WITH MILD HFE HEMOCHROMATOSIS}

Edouard Bardou-Jacquet ${ }^{1-2}$, Jeff Morcet $^{3}$, Ghislain Manet ${ }^{3}$, Fabrice Lainé ${ }^{1,3}$, Michèle Perrin ${ }^{3}$, Anne-Marie Jouanolle $^{6}$,_Dominique Guyader ${ }^{1-2,4}$, Romain Moirand ${ }^{1-2,4}$, Jean-François Viel ${ }^{4-5}$, Yves Deugnier ${ }^{1-4}$

${ }^{1}$ CHU Rennes, Service des maladies du foie, F-35033, Rennes, France

${ }^{2}$ INSERM, U991, Hôpital Pontchaillou, F-35033, Rennes, France

${ }^{3}$ INSERM, CIC 1414, Hôpital Pontchaillou, F-35033, Rennes, France

${ }^{4}$ Univ Rennes1, UFR médecine, F-35043, Rennes, France

${ }^{5}$ CHU Rennes, Service d'épidémiologie et de santé publique, Hôpital Pontchaillou, F-35033, Rennes, France

${ }^{6}$ CHU Rennes, Service de génétique moléculaire, F-35033, Rennes, France

Address for correspondence:

Edouard Bardou-Jacquet, $\mathrm{MD}, \mathrm{PhD}$,

Service des maladies du foie, CHU Pontchaillou, 2 rue Henri Le Guilloux, 35033 Rennes, France

E mail : edouard.bardou-jacquet@ chu-rennes.fr

Phone: +332992842 97; FAX: +33299284112

Word-count : 5045

Number of Figure and Table: 3

Abbreviations: SMR: Standardized Mortality Rates. Hazards Ratio: HR

Conflict of interest: The authors declare that they have no conflict of interest regarding this study.

Financial support: This study was supported by grants from the Programme Hospitalier de Recherche Clinique (PHRC national 2009), the Agence Nationale de la Recherche (ANR 2009), the Comité de la Recherche Clinique de Rennes (COREC 2011), and the Association Fer et Foie.

\section{Authors's contribution}

EBJ made literature search, interpreted the data and wrote the manuscript. JM performed statistical analysis. GM made literature search and analyzed the data. MP collected the data and performed quality control of database. 
AMJ performed the genetic testing, interpreted the data and gave significant contribution to the manuscript. FL,

DG and RM interpreted the data and gave significant contribution to the manuscript. JFV analyzed the data and gave significant contribution to the manuscript. YD supervised the cohort, interpreted the data and gave significant contribution to the manuscript. 


\section{ABSTRACT}

Backround: Mortality studies in patients with hemochromatosis gave conflicting results especially with respect to extrahepatic causes of death. Our objective was to assess mortality and causes of death in a cohort of $H F E$ C282Y homozygotes diagnosed since the availability of HFE testing.

Methods: We studied 1085 C282Y homozygotes consecutively diagnosed from 1996 to 2009 and treated according to current recommendations. Mortality and causes of death were obtained from death certificates and compared to those of the general population. Standardized mortality ratios (SMR) were used to assess specific causes of death and Cox's model to identify prognostic factors for death.

Results: Patients were followed for $8.3 \pm 3.9$ years. Overall SMR was the same as in the general population $(0.94$

- CI:0.71-1.22). Patients with serum ferritin $\geq 2000 \mu \mathrm{g} / \mathrm{L}$ had increased liver-related deaths (SMR: 23.9-CI:13.938.2), especially due to hepatic cancer (SMR: 49.1-CI:24.5-87.9). Patients with serum ferritin between normal and $1000 \mu \mathrm{g} / \mathrm{L}$ had lower mortality than the general population (SMR: 0.27-CI:0.1-0.5) due to decreased mortality related to cardiovascular events and extrahepatic cancers in the absence of increased liver-related mortality. Age, diabetes, alcohol consumption, and hepatic fibrosis were independent prognostic factors of death.

Conclusion: In treated HFE hemochromatosis, only patients with serum ferritin higher than $2000 \mu \mathrm{g} / \mathrm{L}$ have increased mortality, mainly related to liver diseases. Those with mild iron burden have decreased overall mortality in relation to reduced cardiovascular and extrahepatic cancer-related mortality. These results support a beneficial effect of early and sustained management of patients with iron excess, even when mild.

\section{Word count: 244}

Keywords: iron overload, HFE, hemochromatosis, survival, cancer, cardio-vascular disease 


\section{INTRODUCTION}

Major advances have been made to our understanding of iron metabolism and the diagnosis and management of genetic hemochromatosis since early studies by Niederau et al.[1] Progress in molecular genetics has increased the precision and reliability of diagnosis of most genetic defects responsible for iron overload. HFE hemochromatosis has been shown to account for up to $95 \%$ of hemochromatosis in adults,[2-4] to be mainly related to the $\mathrm{C} 282 \mathrm{Y}$ mutation, [5] to be characterized by low clinical penetrance (1\% in women, $28 \%$ in men), [6, 7] and to be diagnosed nowadays at an earlier stage, thanks to widespread family screening and serum-ferritin analysis. [8]

However, despite a significant number of epidemiological studies, the real impact of $H F E$ hemochromatosis on mortality is still unclear, especially with respect to the respective roles of hepatic and extra hepatic diseases in mortality of patients and to the level of iron burden associated with decreased survival. These conflicting results may in part be explained by the various designs of studies. In the pivotal study by Niederau et al.[9] overall mortality was increased, and the main causes of death were cirrhosis, liver cancer, and, cardiomyopathy. In the absence of $H F E$ testing, it is likely that other causes of iron overload, especially non-HFE hemochromatosis and iron-overload secondary to end-stage cirrhosis, were also included. In addition, due to the phenotypic definition of HFE hemochromatosis, the most severe clinical cases were selected, resulting in overrepresentation of cirrhosis (56\%) and diabetes (47\%). This likely induced an overestimation of mortality rates. Milman et al. have draw the same conclusions [10], but their study had the same limitations. More recently, Elmberg et al. [11] reported on 3832 patients with putative hemochromatosis who had been diagnosed using heterogeneous methods between 1964 and 2005. They found an overall increased mortality, which, surprisingly, further increased through time. Fracanzani et al. reported on 452 patients diagnosed prospectively between 1977 and 2007, [8] of whom 269 only were demonstrated to be C282Y HFE homozygotes. They found lower overall survival rates without any difference between $H F E$ and non-HFE hemochromatosis. However, HFE testing was not available and other causes of iron overload or cofactors may have influenced both diagnoses and mortality rates. On the other hand, large scale genotyping studies conducted in general populations included all C282Y homozygotes, but had low power due to the small number of cases with variable clinical expression, resulting in a risk to underestimate disease consequences [7, 12, 13]. In addition, information regarding iron burden and its treatment were either lacking or insufficient. [6,7] Recently serum ferritin levels higher than $1000 \mu \mathrm{g} / \mathrm{l}$ were reported to be associated with increased risk of death in a cohort of 422 North American C282Y homozygotes. [14] 
This led us to reassess the mortality and causes of death in a large, well-defined, and prospective cohort of C282Y HFE homozygous patients and to compare their results with those of the French general population. 


\section{PATIENTS AND METHODS}

\section{Patients}

All C282Y HFE homozygous patients referred as probands to our tertiary center or who were diagnosed through family-screening procedures run by our center since 1996 were prospectively included in the LOGIFER cohort. Patients diagnosed before 1996 were not included because of the likelihood of selection bias caused by retrospective $H F E$ testing. Data from patients' files were recorded by data-managers with double data entry. Clinical research assistant (MP) provided quality control, and bio-statistician (JM) performed coherence control and statistical analyses.

According to French law, the corresponding database was declared to the national committee of "Informatics and Freedom" (CNIL). The study protocol was approved by the local ethics committee (11.27-22/09/2011)

\section{Outcomes and follow-up}

\section{At diagnosis}

The following data were collected at diagnosis: date, age, gender, proband or relative status, alcohol consumption, tobacco smoking, body-mass index, blood pressure, clinical presentation and symptoms (asthenia, diabetes, cardiomyopathy, liver disease, hypogonadism, arthropathy), iron status (serum ferritin, transferrin and iron, transferrin saturation), and routine biochemical features.

Liver fibrosis was determined by a liver biopsy using the METAVIR scoring system (F0: no fibrosis to F4: cirrhosis).[15] In the absence of histological data, patients with serum ferritin $<1000 \mu \mathrm{g} / \mathrm{L}$ were considered to be free of F3-4 fibrosis (= severe fibrosis) according to Guyader's algorithm, [16] those with hepatocellular carcinoma as having severe fibrosis, and others as having missing data. 


\section{During follow-up}

Venesection therapy was advised when serum ferritin was higher than $300 \mu \mathrm{g} / \mathrm{L}$ in men and $200 \mu \mathrm{g} / \mathrm{L}$ in women, or, when both transferrin saturation was higher than $50 \%$ and functional symptoms attributable to hemochromatosis, i.e. chronic fatigue and distal arthralgias, were present. After serum ferritin $<50 \mu \mathrm{g} /$ level was achieved, patients were advised to continue venesection therapy to maintain serum ferritin $<50 \mu \mathrm{g} / \mathrm{L}$ in the long term. Follow-up data were recorded when available: date, number and volume of phlebotomies, and usual clinical and biochemical indicators of tolerance and efficacy of venesection therapy.

The amount of iron removed refers to the number of grams of iron removed until low body-iron stores were achieved. It was calculated assuming that $1 \mathrm{~L}$ of blood contained $0.5 \mathrm{~g}$ of iron. For patients with normal iron parameters at diagnosis, yearly biological surveillance was proposed and treatment was initiated if the above criteria were fulfilled.

\section{End point}

End point was fixed as December 31, 2010, because of delay needed to obtain data on the causes of death. Vital status and causes of death were obtained from death certificates which are collected for the entire French population and supplied by INSEE (National Institute of Statistics and Economical Studies) and INSERM (National Institute of Health and Medical Research). Data on rates and causes of death for the French general population were obtained from the national statistical tables published by these two institutes and based on death certificates. These tables were stratified by date, geographic area, gender, and into 10-year age groups. Causes of death were displayed according to the CIM-10 classification and grouped by broad category which were all studied separately (all causes, non-liver related disease (i.e. all medical causes except liver related disease), liver related disease (i.e. liver failure and liver cancer), liver cancer, extra hepatic cancer, cardiovascular disease, other disease (i.e. neither cardiovascular nor liver related disease, including external causes (i.e. traumatism, suicide, etc.)) 


\section{Statistical analysis}

Statistical analyses were performed using SAS V9.3 (SAS Institute, USA).

\section{Mortality and Causes of death}

The numbers of deaths observed in the cohort, and in subgroups of patients, were compared to the numbers of deaths expected from the general population (Standardized Mortality Ratios [SMRs]). All calculations were stratified by strata according to 5 French administrative geographical areas, sex, 10 year-age groups, and oneyear calendar periods. Therefore, for each stratum, the number of expected deaths was calculated by multiplying the patient-years at-risk by the corresponding national mortality rate. Then SMR determined for a given subgroup was calculated as the ratio of observed deaths divided by the sum of the expected number of deaths in the corresponding strata. SMRs were calculated for general causes of death, including deaths from external causes. The $95 \%$ confidence interval (CI) was determined on the basis of a $5 \%$ bilateral test using the Byar approximation.

\section{Prognostic factors of death}

Prognostic factors of death were first determined by univariate analyses using Student's t-test or Wilcoxon's test for continuous variables, and the chi-squared test or Fisher's exact test for categorical variables. Then multivariate survival analyses were performed using Cox's regression model to estimate the hazards ratio (HR) with a $95 \%$ CI.

Variables with $p<0.2$ in the univariate analyses were introduced into the multivariate models. We used multiple imputation inference for variables with less than $30 \%$ missing data. Missing data were filled in 30 times to generate 30 complete data sets with MI procedure from SAS 9.3. Then, the 30 complete data sets were analyzed by using Cox regression procedures, and the results from these sets were combined for the inference study, by using MIANALYZE procedure from SAS 9.3.

A $p$ value of $<0.05$ was considered as significant. 


\section{RESULTS}

\section{Cohort characteristics}

1085 HFE C282Y homozygous patients were consecutively diagnosed between 1996 and 2009. Their main characteristics are presented in Table 1. Initial referral causes were iron-related symptoms in 306 patients, abnormal iron tests at routine check-up in 401 patients, family screening in 336 patients and unknown in 42 patients. Based on serum ferritin levels at diagnosis, 212 had normal value, 531 patients were considered to have slight iron burden (serum ferritin levels from normal to less than $1000 \mu \mathrm{g} / \mathrm{L}$ ), 135 mild iron burden (serum ferritin

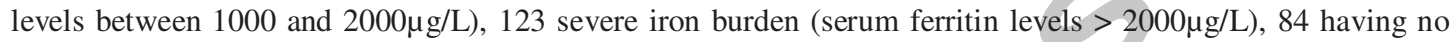
serum ferritin determination available at diagnosis. At diagnosis, 789 patients had serum ferritin levels greater than the normal range and were thus advised to undergo venesection therapy. Despite all subjects were not treated in our unit, we can ensure that phlebotomies were really started and iron removal achieved in 698 of them. Therefore, our study must be analysed on "intent to treat" rather than "per protocol" basis.

\section{Overall mortality and causes of death}

Overall mortality and causes of death are reported in Table 2. Incidence rates of liver disease and liver cancer related deaths were 2.92 and 2.16 per 1000 person years respectively. Incidence rate of extra hepatic cancer and cardiovascular related deaths were 0.97 and 0.54 per 1000 person years respectively. Despite overall mortality was the same that the general population, hepatic causes of death were increased whilst extrahepatic causes of death were reduced. Hepatic and nonhepatic-related deaths occurred at the age of $63.8( \pm 10.1)$ and $67( \pm 14)$ years, respectively $(p=0.33$, without difference in the mean age at diagnosis $(59 \pm 9.8$ and $61.8 \pm 13.7$ years, respectively $(p=0.4))$ or in the duration of median follow-up $(4.7 \pm 3$ and $5.2 \pm 3.2$ years, respectively $(p=0.55))$. Mean serum ferritin levels of patients who died from hepatic causes was $3816 \pm 1932 \mu \mathrm{g} / \mathrm{L}$, and $2417 \pm 3723 \mu \mathrm{g} / \mathrm{L}(p=0.11)$ in patients who died from non-liver related causes.

SMRs did not vary according to male or female gender, proband/relative status, year of birth and year of diagnosis.

SMRs were similar to that of the general population for age at diagnosis lower than 45 years, between 45 and 55 , and higher than 56. All had similar mortality to that of the general population but had increased risk of death from liver cancer compared to the general population. 


\section{Mortality and causes of death according to disease expression at diagnosis}

As the expressivity of HFE hemochromatosis is highly variable, the specific causes of death were studied according to initial iron burden and clinical expression. SMRs for relevant variables are presented in Table 3.

\section{Iron burden}

Serum ferritin levels at diagnosis.

Patients with serum ferritin levels between normal and $1000 \mu \mathrm{g} / \mathrm{L}$ had lower overall mortality, which corresponded to reduced cardiovascular and extra hepatic cancer-related mortality whereas liver-related mortality remained similar to that of the general population. Patients with serum ferritin levels from $1000 \mu \mathrm{g} / \mathrm{L}$ to $2000 \mu \mathrm{g} / \mathrm{L}$ had similar SMRs to those of the general population. Patients with serum ferritin levels greater than $2000 \mu \mathrm{g} / \mathrm{L}$ had higher mortality, mostly related to liver cancer, and without decreased cardiovascular and extra hepatic-related mortality.

Patients with normal serum ferritin at diagnosis had similar SMR to that of the general population except for liver cancer (SMR: 48.78 (5.48-176.12)). This result was due to 2 patients with normal serum ferritin at diagnosis who died from liver cancer, while 0.04 liver cancer-related death was expected. The first patient was a female with serum ferritin of $186 \mu \mathrm{g} / \mathrm{L}$ at diagnosis. She had overt metabolic syndrome and died 11 years later, at the age of 74 years, from hepatocellular carcinoma. It is likely that she had no cirrhosis at the time of the diagnosis of $\mathrm{HH}$ and that she developed cirrhosis related to nonalcoholic steato-hepatitis during follow-up. The second patient had unclear history of severe mixed, alcoholic and hemochromatotic cirrhosis revealed by digestive bleeding with early death after admission. His initial low serum ferritin level may have been related to bleeding or to unknown previous venesection therapy, hence leading to somehow inadequate categorization of the patient as "normal serum ferritin". With the exception of these two patients, for which the link between cirrhosis and HFE hemochromatosis was highly questionable, the eighteen remaining patients who died from hepatocellular carcinoma had serum ferritin higher than $2000 \mu \mathrm{g} / \mathrm{L}$ at diagnosis.

Transferrin saturation at diagnosis. 
Patients with serum transferrin saturation lower than $75 \%$ at diagnosis had reduced mortality compared to the general population (SMR:0.56 (CI:0.30-0.96)), whereas patients with transferrin saturation greater than $75 \%$ had similar mortality (SMR:1.03 (CI:0.70-1.46)) .

Amount of iron removed.

Patients with mild amount of iron removed $(2-10 \mathrm{~g}, \mathrm{n}=397)$ had lower overall mortality (SMR:0.23 (0.08-0.5) than the general population, whilst the mortality of patients with high amount of iron removed $(>10 \mathrm{~g})$ did not differ from that of the general population (SMR:1.01 (0.37-2.2)).

\section{Clinical expression}

Cirrhosis: Liver biopsy was performed in 254 patients. Patients with cirrhosis ( $\mathrm{n}=51$ ) had higher mortality than that of the general population (SMR:4.43 (2.53-7.19)) mainly due to increased liver disease- and liver cancerrelated mortality (SMR: 7.39 (1.99-18.93) and SMR:86.02 (37.04-169.51) respectively). The overall mortality of patients with F0 to F2 fibrosis was lower than that of the general population (SMR:0.45 (0.16-0.97)).

Diabetes: Patient with diabetes had increased mortality (SMR:4.07 (2.45-6.35)) mainly related to increased liver disease and liver cancer-related mortality (SMR:41.67 (20.77-74.56) and SMR:92.11 (36.9-189.78) respectively). By contrast, those without diabetes had lower mortality than the general population (SMR:0.52 (0.32-0.79)), although they had increased liver cancer-related mortality (SMR:4.98 (1.34-12.75) and lower extra hepatic cancer-related mortality (SMR: $0.21(0.04-0.61))$.

Arthropathy: Patients with arthropathy and patient without arthropathy at diagnosis had similar mortality to that of the general population (SMR:0.81 (0.47-1.3) and SMR:0.86 (0.53-1.31) respectively).

Cardiomyopathy: Patients with cardiomyopathy at diagnosis $(\mathrm{N}=34)$ - whether it was related or not to hemochromatosis - had significantly increased mortality (SMR:3.37 (1.54-6.41)). 


\section{Patients presentation according to main causes of death}

Cardiovascular causes of death: Five patients died from cardiovascular disease (SMR:0.38 (CI:0.12-0.89))

(Table 2). Serum ferritin levels $<1000 \mu \mathrm{g} / \mathrm{L}$ at diagnosis, and amount of iron removed between 2 and $10 \mathrm{~g}$ were associated with lower cardiovascular mortality. Other variables were not found to influence cardiovascular mortality.

Hepatic causes of death (including liver cancer): Twenty seven patients died from liver-related deaths (SMR:6.85 (CI:4.51-9.97)) (Table 2). They were mainly males (21/27) with severe iron burden at diagnosis (mean serum ferritin: $3816 \pm 1932 \mu \mathrm{g} / \mathrm{L}$ ). Ten had excessive alcohol consumption, 19 had severe fibrosis and 11 had diabetes. Among these 27 patients, 20 patients died from hepatic cancer compared to 1.25 expected in the general population (SMR:15.96 (CI:9.75-24.65)). Severe fibrosis at initial liver biopsy was associated with higher mortality as were type I and type II diabetes.

Extrahepatic cancers: Nine patients died from extrahepatic cancers compared to 21.81 expected in the general population (Table 2). Patients with a mild amount (2-10g) of iron removed and/or serum ferritin levels $<1000 \mu \mathrm{g} / \mathrm{L}$ had lower mortality related to extrahepatic cancers than the general population (SMR:0.21 (CI:0.02$0.78)$ and 0.19 (CI:0.02-0.69) respectively).

\section{Factors associated with mortality}

Cox's proportional hazards model was performed to assess the prognostic factors associated to death. Variables significant $(p<0.2)$ at univariate analyses were introduced into multivariate models. Age at diagnosis $\geq 56$ (HR: 7.72 [4.35-13.71]), diabetes (HR: 4.69 [2.51-8.77]), alcohol consumption (HR: 3.20 [1.68-6.09]), and liver fibrosis $\geq$ F3 (HR: 6.80 [3.62-12.76]) were independently associated with the risk of death. Figure 1 shows Kaplan Meier cumulative survival curves according to factors associated with mortality. 


\section{DISCUSSION}

Our study indicates that HFE C282Y homozygous patients diagnosed since 1996 - when $H F E$ testing became available - and who were treated according to current international recommendations, did not have increased overall mortality rate compared to general population. Moreover, it demonstrates that, by contrast to patients with serum ferritin higher than $2000 \mu \mathrm{g} / \mathrm{L}$ who have increased mortality, mainly related to liver diseases, patients with serum ferritin between normal and $1000 \mu \mathrm{g} / \mathrm{L}$ have decreased overall mortality in relation to reduced cardiovascular and extrahepatic cancer - related mortality in the absence of increased liver-related mortality. This was not observed in patients with normal serum ferritin at diagnosis.

The present study has several strengths. First, it relies upon a well-documented prospective cohort of 1085 patients, diagnosed consecutively by genotyping and presenting a wide spectrum of biochemical and clinical phenotypic expression of the disease, including 789 (73\%) patients with increased serum ferritin levels at

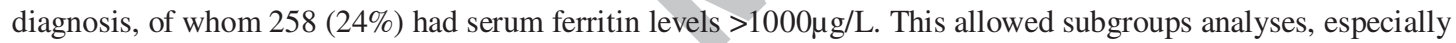
according to initial iron burden and clinical presentation. Second, thanks to the French social insurance system, the record of death causes was exhaustive in both patients and the general population used as reference. Third, we used the SMR method to compare the mortality of patients to that of general population, allowing sex- and age-specific adjustment across time period and geographic area, and then, avoiding competing biases between causes of death. Otherwise, two main limitations have to be underlined. First, the mean duration of follow-up was rather short $(8.3 \pm 3.9$ years $)$ with respect to a disease with a long-standing course, and thus, the number of deaths remained low (59/1085). Second, detailed history of maintenance therapy was fragmented even if data regarding the initiation of treatment was available for a large number of patients. 


\section{Overall mortality and prognostic factors}

Overall life expectancy was normal in the present cohort. This could not be related to earlier diagnosis, since age at diagnosis was similar to those observed by Niederau et al.[9] and Fracanzani et al. [8] Explanations may be a higher proportion of females who are known to have less severe disease,[17] and/or a trend towards less severe disease through time [8] possibly due to lower prevalence of associated co-morbidities. The higher proportion of of females found in the present study is in line with the autosomal transmission of $\mathrm{HH}$ and better reports on the reality of the disease. It is likely the consequence of widespread genetic testing in both index and family cases and better awareness of the disease, leading to diagnose less severe forms. This increasing proportion of females over time was already described in the study by Fracanzani et al.[8]

However, 789 (73\%) of our patients had increased serum ferritin levels at diagnosis, including 258(24\%) with serum ferritin $>1000 \mu \mathrm{g} / \mathrm{L}$, which makes our cohort representative of the current $H F E$ hemochromatosis population with a wide range in clinical expression. Finally, the overall mortality in our cohort could also have been influenced by the beneficial effect of early and sustained venesection therapy.

Cox regression model showed that age at diagnosis $\geq 56$ years, diabetes, alcohol consumption, and liver fibrosis $\geq$ F3 were independently associated with the risk of death. One may be surprised by the absence of serum ferritin in the model, but serum ferritin being used in the definition of fibrosis stage, it was more statistically sound not to consider it for the analysis.

\section{Causes of death and iron burden}

As expected, mortality was mostly (47\%) related to liver disease, mainly hepatic cancer $(74 \%)$. Of note, liverrelated deaths mainly occurred in patients with marked iron burden, severe fibrosis and associated co-morbidities such as diabetes. This emphasizes the critical importance of fibrosis staging at the time of diagnosis and, in those patients with severe fibrosis, of biannual ultra sound examination, even after achievement of iron removal.

SMRs related to extrahepatic causes of death were significantly decreased in the whole cohort. Interestingly, this was due to decreased cardiovascular and extrahepatic cancer-related mortality only in patients with serum ferritin levels comprised between the upper limit of normal and $1000 \mu \mathrm{g} / \mathrm{L}$ (Table 3). As these patients did not have higher mortality due to liver disease, this could not be due to a competing effect between causes of death. 
Moreover, this decreased mortality was not observed in patients with normal serum ferritin levels at diagnosis which were not advised to be venesected. Similar results were obtained when studying patients with amount of iron removed between 2 and $10 \mathrm{~g}$.

By contrast, patients with iron removed $>10 \mathrm{~g}$ or serum ferritin higher than $1000 \mu \mathrm{g} / \mathrm{L}$ had similar cardiovascular and extrahepatic cancer-related mortality as the general population. Such a difference was not due to earlier liver-related mortality as hepatic and nonhepatic-related deaths occurred at the same age and duration of followup, and because this was even observed in patients with serum ferritin between 1000 and $2000 \mu \mathrm{g} / \mathrm{L}$ who did not have increased risks for liver cancer-related mortality.

Previous results on cardiovascular mortality in hemochromatosis have been conflicting, $[9,10]$ and the relevance of C282Y HFE mutation as a risk factor for cardiovascular events is still debated. [18, 19] Serum ferritin is likely a marker of cardiovascular complications possibly through its link with insulin resistance. [20] However, Valenti et al. did not find any association between increased serum ferritin levels and the development of carotid plaque in patients with HFE mutations unlike in those free of HFE mutations. [21] This suggests that, in hemochromatosis, a balance between the potential benefits of HFE mutations and the deleterious effect of iron overload could exist. [22] Our results support a protective effect of HFE hemochromatosis on the development of cardiovascular disorders. This could be due to the iron-poor phenotype of macrophages in $H F E$ hemochromatosis, [23] protecting these cells from the deleterious effect of iron. [24] However, this beneficial effect was observed in our patients with serum ferritin levels comprised between the normal range and $1000 \mu \mathrm{g} / \mathrm{L}$, but not in those with normal serum ferritin values at diagnosis. This would support a beneficial effect of sustained iron depletion rather than of the sole HFE status.

Contrary to previous follow-up studies of hemochromatosis patients, $[25,26]$ we found a lower extra-hepatic cancers mortality. This was not related to early death secondary to liver disease. According to initial iron burden, only the subgroup of patients with serum ferritin levels comprised between normal and $1000 \mu \mathrm{g} / \mathrm{L}$ had decreased extra-hepatic cancer-related mortality, which again would suggest a beneficial role of chronic iron depletion. Many epidemiological and experimental studies support a role of iron as a carcinogen. Conversely, iron depletion has been shown to be associated with a dramatic decrease in the incidence of extra-hepatic cancers in patients with peripheral arterial disease.[27] However, such a beneficial effect in hemochromatosis patients 
could be also related to medical follow-up or to lifestyle modifications due to the awareness of a genetic condition or even to a biological advantage of the HFE C282Y mutation.

The present results must be interpreted on in "intent to treat" basis. They suggest that early and sustained iron removal is beneficial to hemochromatosis patients, especially in cases of slight or mild iron overload, and that any reduction in the venesection schedule should be introduced cautiously. However, more precise data from all patients regarding long-term stringency of maintenance therapy, morbidities that occurred during follow-up, and evolution of exposure to co-morbidity factors after the initial removal of excess iron would have been necessary to state about the real effect of iron depletion on survival.

In conclusion, we have shown, in a large population of treated patients, that overall mortality is not increased in HFE hemochromatosis. Actually, this reflects opposite situations: patients with serum ferritin higher than $2000 \mu \mathrm{g} / \mathrm{L}$ have increased liver-related mortality, and those with serum ferritin between normal and $1000 \mu \mathrm{g} / \mathrm{L}$, when treated, have decreased cardiovascular and extra-hepatic related mortality despite normal liver-related mortality. Our results support a beneficial effect of early management and sustained follow-up of patients with iron excess, even when slight, whateyer this protective effect is really related to iron removal or not. 


\section{REFERENCES}

[1] Niederau C, Fischer R, Sonnenberg A, Stremmel W, Trampisch HJ, Strohmeyer G. Survival and causes of death in cirrhotic and in noncirrhotic patients with primary hemochromatosis. The New England journal of medicine 1985;313:1256-1262.

[2] Brissot P, Moirand R, Jouanolle AM, Guyader D, Le Gall JY, Deugnier Y, et al. A genotypic study of 217 unrelated probands diagnosed as "genetic hemochromatosis" on "classical" phenotypic criteria. Journal of hepatology 1999;30:588-593.

[3] Bacon BR, Olynyk JK, Brunt EM, Britton RS, Wolff RK. HFE genotype in patients with hemochromatosis and other liver diseases. Annals of internal medicine 1999;130:953-962.

[4] Crawford DH, Jazwinska EC, Cullen LM, Powell LW. Expression of HLA-linked hemochromatosis in subjects homozygous or heterozygous for the C282Y mutation. Gastroenterology 1998;114:1003-1008.

[5] Moirand R, Jouanolle AM, Brissot P, Le Gall JY, David V, Deugnier Y. Phenotypic expression of HFE mutations: a French study of 1110 unrelated iron-overloaded patients and relatives. Gastroenterology 1999;116:372-377.

[6] Allen KJ, Gurrin LC, Constantine CC, Osborne NJ, Delatycki MB, Nicoll AJ, et al. Iron-overload-related disease in HFE hereditary hemochromatosis. The New England journal of medicine 2008;358:221-230.

[7] Beutler E, Felitti VJ, Koziol JA, Ho NJ, Gelbart T. Penetrance of 845G--> A (C282Y) HFE hereditary haemochromatosis mutation in the USA. Lancet 2002;359:211-218.

[8] Fracanzani AL, Piperno A, Valenti L, Fraquelli M, Coletti S, Maraschi A, et al. Hemochromatosis in Italy in the last 30 years: role of genetic and acquired factors. Hepatology 2010;51:501-510.

[9] Niederau C, Fischer R, Purschel A, Stremmel W, Haussinger D, Strohmeyer G. Long-term survival in patients with hereditary hemochromatosis. Gastroenterology 1996;110:1107-1119.

[10] Milman N, Pedersen P, a Steig T, Byg KE, Graudal N, Fenger K. Clinically overt hereditary hemochromatosis in Denmark 1948-1985: epidemiology, factors of significance for long-term survival, and causes of death in 179 patients. Annals of hematology 2001;80:737-744.

[11] Elmberg M, Hultcrantz R, Ebrahim F, Olsson S, Lindgren S, Loof L, et al. Increased mortality risk in patients with phenotypic hereditary hemochromatosis but not in their first-degree relatives. Gastroenterology 2009;137:1301-1309.

[12] Andersen RV, Tybjaerg-Hansen A, Appleyard M, Birgens H, Nordestgaard BG. Hemochromatosis mutations in the general population: iron overload progression rate. Blood 2004;103:2914-2919.

[13] Pankow JS, Boerwinkle E, Adams PC, Guallar E, Leiendecker-Foster C, Rogowski J, et al. HFE C282Y homozygotes have reduced low-density lipoprotein cholesterol: the Atherosclerosis Risk in Communities (ARIC) Study. Translational research : the journal of laboratory and clinical medicine 2008;152:3-10.

[14] Barton JC, Acton RT, So J, Chan S, Adams PC. Increased Risk of Death From Iron Overload Among 422 Treated Probands With HFE Hemochromatosis and Serum Levels of Ferritin Greater Than $1000 \mathrm{mug} / \mathrm{L}$ at Diagnosis. Clinical gastroenterology and hepatology : the official clinical practice journal of the American Gastroenterological Association 2012.

[15] Bedossa P, Poynard T. An algorithm for the grading of activity in chronic hepatitis C. The METAVIR Cooperative Study Group. Hepatology 1996;24:289-293.

[16] Guyader D, Jacquelinet C, Moirand R, Turlin B, Mendler MH, Chaperon J, et al. Noninvasive prediction of fibrosis in C282Y homozygous hemochromatosis. Gastroenterology 1998;115:929-936. 
[17] Moirand R, Adams PC, Bicheler V, Brissot P, Deugnier Y. Clinical features of genetic hemochromatosis in women compared with men. Annals of internal medicine 1997;127:105-110.

[18] Tuomainen TP, Kontula K, Nyyssonen K, Lakka TA, Helio T, Salonen JT. Increased risk of acute myocardial infarction in carriers of the hemochromatosis gene Cys282Tyr mutation : a prospective cohort study in men in eastern Finland. Circulation 1999;100:1274-1279.

[19] Engberink MF, Povel CM, Durga J, Swinkels DW, de Kort WL, Schouten EG, et al. Hemochromatosis (HFE) genotype and atherosclerosis: Increased susceptibility to iron-induced vascular damage in C282Y carriers? Atherosclerosis 2010;211:520-525.

[20] Jehn M, Clark JM, Guallar E. Serum ferritin and risk of the metabolic syndrome in U.S. adults. Diabetes care 2004;27:2422-2428.

[21] Valenti L, Swinkels DW, Burdick L, Dongiovanni P, Tjalsma H, Motta BM, et al. Serum ferritin levels are associated with vascular damage in patients with nonalcoholic fatty liver disease. Nutrition, metabolism, and cardiovascular diseases : NMCD 2011;21:568-575.

[22] Sullivan JL. Do hemochromatosis mutations protect against iron-mediated atherogenesis? Circulation Cardiovascular genetics 2009;2:652-657.

[23] Garuti C, Tian Y, Montosi G, Sabelli M, Corradini E, Graf R, et al. Hepcidin expression does not rescue the iron-poor phenotype of Kupffer cells in Hfe-null mice after liver transplantation. Gastroenterology 2010;139:315-322 e311.

[24] Kraml PJ, Klein RL, Huang Y, Nareika A, Lopes-Virella MF. Iron loading increases cholesterol accumulation and macrophage scavenger receptor I expression in THP-1 mononuclear phagocytes. Metabolism: clinical and experimental 2005;54:453-459.

[25] Fracanzani AL, Conte D, Fraquelli M, Taioli E, Mattioli M, Losco A, et al. Increased cancer risk in a cohort of 230 patients with hereditary hemochromatosis in comparison to matched control patients with noniron-related chronic liver disease. Hepatology 2001;33:647-651.

[26] Osborne NJ, Gurrin LC, Allen KJ, Constantine CC, Delatycki MB, McLaren CE, et al. HFE C282Y homozygotes are at increased risk of breast and colorectal cancer. Hepatology 2010;51:1311-1318.

[27] Zacharski LR, Chow BK, Howes PS, Shamayeva G, Baron JA, Dalman RL, et al. Decreased cancer risk after iron reduction in patients with peripheral arterial disease: results from a randomized trial. Journal of the National Cancer Institute 2008;100:996-1002. 
Table 1: Main clinical and biochemical characteristics of patients.

\begin{tabular}{|c|c|}
\hline Gender (males / females - \% (n)) & $48 \% / 52 \%(516 / 569)$ \\
\hline Probands/relatives \% (n) & $69 \% / 31 \%(749 / 336)$ \\
\hline Age at diagnosis (years) (mean \pm SD) & $45.2( \pm 14.2)$ \\
\hline Follow up duration (years) (mean \pm SD) & $8.3( \pm 3.9)$ \\
\hline 10-year survival (\%) & 94.7 \\
\hline \multicolumn{2}{|l|}{ Serum ferritin $(\mu \mathrm{g} / \mathrm{L})$} \\
\hline Mean \pm SD & $981( \pm 1419)$ \\
\hline Normal / <1000 / 1000-2000 / >2000 (n) & $212 / 531 / 135 / 12$ \\
\hline Missing data (n) & $8 \%(84)$ \\
\hline \multicolumn{2}{|l|}{ Amount of iron removed (g) } \\
\hline$($ mean \pm SD) & $5.0( \pm 5.1)$ \\
\hline Missing data $(\%[n])$ & $36 \%(387)$ \\
\hline \multicolumn{2}{|l|}{ Liver fibrosis (Metavir score - \% (n)) } \\
\hline F3-F4 (\%) & $8 \%(82)$ \\
\hline$<$ F3 & $76 \%(831)$ \\
\hline Missing data & $16 \%(172)$ \\
\hline \multicolumn{2}{|l|}{ Diabetes \% (n) } \\
\hline Type I \& Type II diabetes & $4 \%(46)$ \\
\hline No diabetes & $70 \%(762)$ \\
\hline Missing data & $26 \%(277)$ \\
\hline \multicolumn{2}{|l|}{ Alcohol consumption \% (n) } \\
\hline$>30$ g/day (>20g / day in women) & $8 \%(88)$ \\
\hline$<30$ g/day $(<20$ g/day in women $)$ & $64 \%(693)$ \\
\hline Missing data & $28 \%(304)$ \\
\hline
\end{tabular}


Table 2 : Overall mortality rates and causes of death of patients. Statistically significant standardized mortality rates (SMR) compared to general population are both in bold and indicated by *. ${ }^{a}$ Extra hepatic cancers : lung (2), kidney (1), pancreas (1), skin (2), colon (1), unknown (2). ${ }^{\text {b }}$ Cardiovascular disorders : Stroke (2), valve replacement (1), coronary disease (2). ${ }^{\text {C }}$ Others : traumatism (1), suicide (2), pyelonephritis (1), kidney failure (1), diabetes (2), Addison disease (1), digestive perforation (1), dementia (2), acute alcohol poisoning (1), cachexia (1), pulmonary fibrosis (1), inhalation (2). Significant value $(p<0,05)$ are in bold and noted by *

Observed $(n) \quad$ Expected $(n) \multimap$ SMR $\quad \mathrm{Cl} 95 \%$

\begin{tabular}{|c|c|c|c|c|}
\hline Hepatic diseases & 27 & 3.94 & $6.85^{*}$ & $4.51-9.97$ \\
\hline Liver cancer & 20 & 1.25 & $15.96 *$ & $9.75-24.65$ \\
\hline Non hepatic diseases & 30 & 56.57 & $0.53^{*}$ & $0.36-0.76$ \\
\hline Extra & 9 & 21.81 & $0.41 *$ & $0.19-0.78$ \\
\hline Cardio-vascular diseases ${ }^{b}$ & 5 & 13.09 & $0.38 *$ & $0.12-0.89$ \\
\hline Oth & 16 & 21.64 & 0.74 & $0.42-1.2$ \\
\hline All causes & 57 & 60.56 & 0.94 & $0.71-1.22$ \\
\hline
\end{tabular}


Table 3: Overall and disease specific Standardized Mortality Ratios according to clinical and biological characteristics of patients.

Normal serum ferritin was defined as $<300 \mu \mathrm{g} / \mathrm{L}$ in men, and $<200 \mu \mathrm{g} / \mathrm{L}$ in women. SMR were considered significant if $95 \%$ confidence interval exclude the value " 1 ". They are in bold and noted by

\begin{tabular}{|c|c|c|c|c|c|}
\hline \multirow[b]{2}{*}{ (N) } & \multicolumn{5}{|c|}{ Mortality (SMR (Cl 95\%)) } \\
\hline & Overall & Cardiovascular & $\begin{array}{c}\text { Liver disease } \\
\text { (including liver cancer) }\end{array}$ & Liver cancer & Extra hepatic cancer \\
\hline \multicolumn{6}{|l|}{ Serum ferritin } \\
\hline Normal (212) & $0.64(0.13-1.87)$ & $0.00(0.00-4.78)$ & $6.90(0.77-24.9)$ & $48.78(5.48-176.12)$ & $0.00(0.00-1.50)$ \\
\hline $\mathrm{N}-1000 \mu \mathrm{g} / \mathrm{L}(531)$ & $0.27(0.12-0.54)^{*}$ & $0.16(0.00-0.87)^{*}$ & $0.00(0.00-1.69)$ & $0.00(0.00-5.60)$ & $0.19(0.02-0.69)^{*}$ \\
\hline $1000-2000 \mu \mathrm{g} / \mathrm{L}(135)$ & $0.81(0.39-1.50)$ & $0.32(0.00-1.79)$ & $0.00(0.00-3.84)$ & $0.00(0.00-11.26)$ & $0.77(0.15-2.24)$ \\
\hline$>2000 \mu \mathrm{g} / \mathrm{L}(123)$ & 2.64 (1.69-3.92)* & $1.11(0.12-4.01)$ & $23.88(13.90-38.23)^{*}$ & $49.11(24.48-87.87)^{*}$ & $0.86(0.17-2.53)$ \\
\hline \multicolumn{6}{|l|}{ Iron removed } \\
\hline$<2 \mathrm{~g}(214)$ & $0.40(0.08-1.17)$ & $0.00(0.00-1.81)$ & $0.00(0.00-7.94)$ & $0.00(0.00-41.03)$ & $0.00(0.00-1.15)$ \\
\hline $2-10 g(397)$ & $0.23(0.08-0.50)^{*}$ & $0.00(0.00-0.53)^{*}$ & $0.59(0.01-3.26)$ & $1.79(0.03-9.97)$ & $0.21(0.02-0.78)^{*}$ \\
\hline$>10 \mathrm{~g}(87)$ & $1.01(0.37-2.20)$ & $0.00(0.00-3.06)$ & $7.39(1.99-18.93)^{*}$ & $23.12(6.22-59.20)^{*}$ & $0.41(0.01-2.28)$ \\
\hline \multicolumn{6}{|l|}{ Liver Fibrosis } \\
\hline Fibrosis 0-2 (181) & $0.45(0.16-0.97)^{*}$ & $0.38(0.00-2.13)$ & $1.00(0.01-5.54)$ & $3.21(0.04-17.83)$ & $0.19(0.00-1.07)$ \\
\hline Fibrosis F3 (22) & $0.91(0.10-3.27)$ & $0.00(0.00-6.70)$ & $11.36(1.28-41.03)^{*}$ & $38.46(4.32-138.87)^{*}$ & $0.00(0.00-3.55)$ \\
\hline Cirrhosis (51) & $4.43(2.53-7.19)^{*}$ & $1.47(0.02-8.17)$ & $37.04(18.46-66.27)^{*}$ & $86.02(37.04-169.51)^{*}$ & $0.00(0.00-2.07)$ \\
\hline \multicolumn{6}{|l|}{ Glucose Metabolism } \\
\hline Normal (762) & $0.52(0.32-0.79)^{*}$ & $0.35(0.07-1.01)$ & $2.28(0.83-4.95)$ & $4.98(1.34-12.75)^{*}$ & $0.21(0.04-0.61)^{*}$ \\
\hline Diabetes (46) & $4.07(2.45-6.35)^{*}$ & $1.53(0.17-5.51)$ & $41.67(20.77-74.56)^{*}$ & $92.11(36.9-189.78)^{*}$ & $1.41(0.16-5.10)$ \\
\hline
\end{tabular}

\section{Figure legends}

Figure 1: Survival according to the presence of identified prognostic factor

Kaplan Meier cumulative survival curves according to age younger or older than 56 at diagnosis (Panel A), the presence of diabetes at diagnosis (Panel B), excessive alcohol consumption at diagnosis (Panel C), and the presence of severe liver fibrosis at diagnosis (Panel D). 


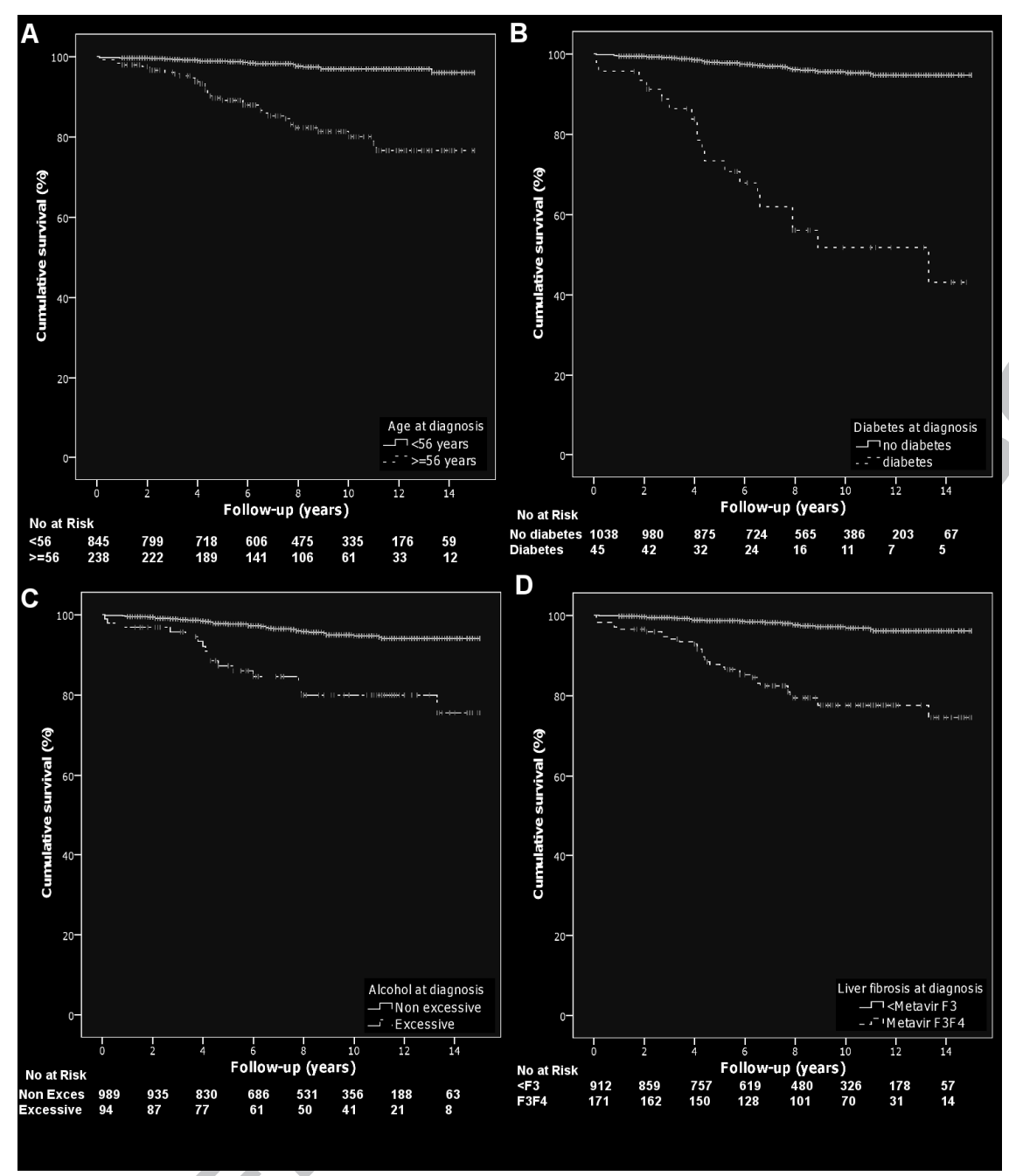

